\title{
О СКЛАДЧАТО-БЛОКОВОМ СТРОЕНИИ СОЛЯНЫХ И НАДСОЛЯНЫХ ОТЛОЖЕНИЙ СОЛИКАМСКОЙ ВПАДИНЫ ПО МАТЕРИАЛАМ НАЗЕМНОЙ И ПОДЗЕМНОЙ СЕЙСМОАКУСТИКИ
}

\author{
И.И. Чайковский \\ Горный институт УрО РАН, г. Пермь
}

\begin{abstract}
Аннотация: Проведена структурно-геологическая интерпретация трех сейсмических временных разрезов на юго-западе Быгельско-Троицкого участка, позволившая выявить в верхней части соляной толщи и нижней части надсоляных два типа структур. Наиболее мелкими (10-35 м) являются коробчатые складки с килевидными синклиналями. Более крупными являются симметричные, расширяющиеся кверху антиклинали (40-65, 150-200, около 320 м), которые могут встречаться по отдельности или образовывать скопления (ансамбли). Субвертикальные границы между ними дают основание предполагать, что на уровне верхней части соляной и нижней части надсоляной толщ как единого массива деформация происходила преимущественно за счет продольного укорочения и/или скольжения слоистой толщи по неровной поверхности соляного ложа.
\end{abstract}

Ключевые слова: Верхнекамское месторождение, временной разрез, складчатость.

О масштабе складчатости отложений Соликамской впадины можно судить по разрезам горных выработок калийных рудников, пройденных преимущественно в верхах сильвинитовой и низах карналлитовой зон, а также по разрезам солеразведочных скважин, расстояние между которыми составляет от 500 до 2000 м. При таком шаге наблюдения получить данные о пликативных структурах меньшего размера весьма проблематично. Спецификой соляной толщи Верхнекамского месторождения является локализация на глубинах 150-500 м, что ограничивает применение классической сейсморазведки.

Для получения более детальной информации о строении верхней части соляной толщи и низов надсоляной были использованы предоставленные лабораторией активной сейсмоакустики ГИ УрО РАН три временных сейсмических разреза протяженностью 520-2000 м широтного и субширотного простирания, пройденные как в горных выработках (пласт АБ), так и с поверхности. Все они располагаются в югозападной части Быгельско-Троицкого участка, характеризующегося полным разрезом водозащитной толщи, то есть максимальной сохранностью соляных пластов в отложениях соликамской свиты. Методика проведения и интерпретации результатов малоглубинных сейсморазведочных работ приведена в следующих публикациях $[2,3]$.

Задачей настоящего исследования являлась интерпретация временных сейсмических разрезов для получения сведений о строении верхней части соляной и нижней части надсоляной толщ, которые недоступны для прямого площадного наблюдения.

Интерпретация заключалась в трассировании отражающих поверхностей, выявлении антиклинальных или синклинальных структур и выделении субвертикальных границ, прерывающих несколько отражающих поверхностей. Структурное дешифрирование данных разрезов позволило установить следующее.

Все разрезы осложнены субвертикальными линеаментами, которые сопоставляются с границами складчатых блоков. «Обрыв» отражающих поверхностей связывается не столько с тектоническими нарушениями, сколько с участками увеличения углов падения пласта, которые сопоставляются нами с килевидными синклиналями.

На фоне относительно горизонтального залегания выделяются единичные участки антиклинального строения (расширяющиеся кверху) и их скопления, иногда перемежаемые участками синклинального строения (сужающиеся кверху). 

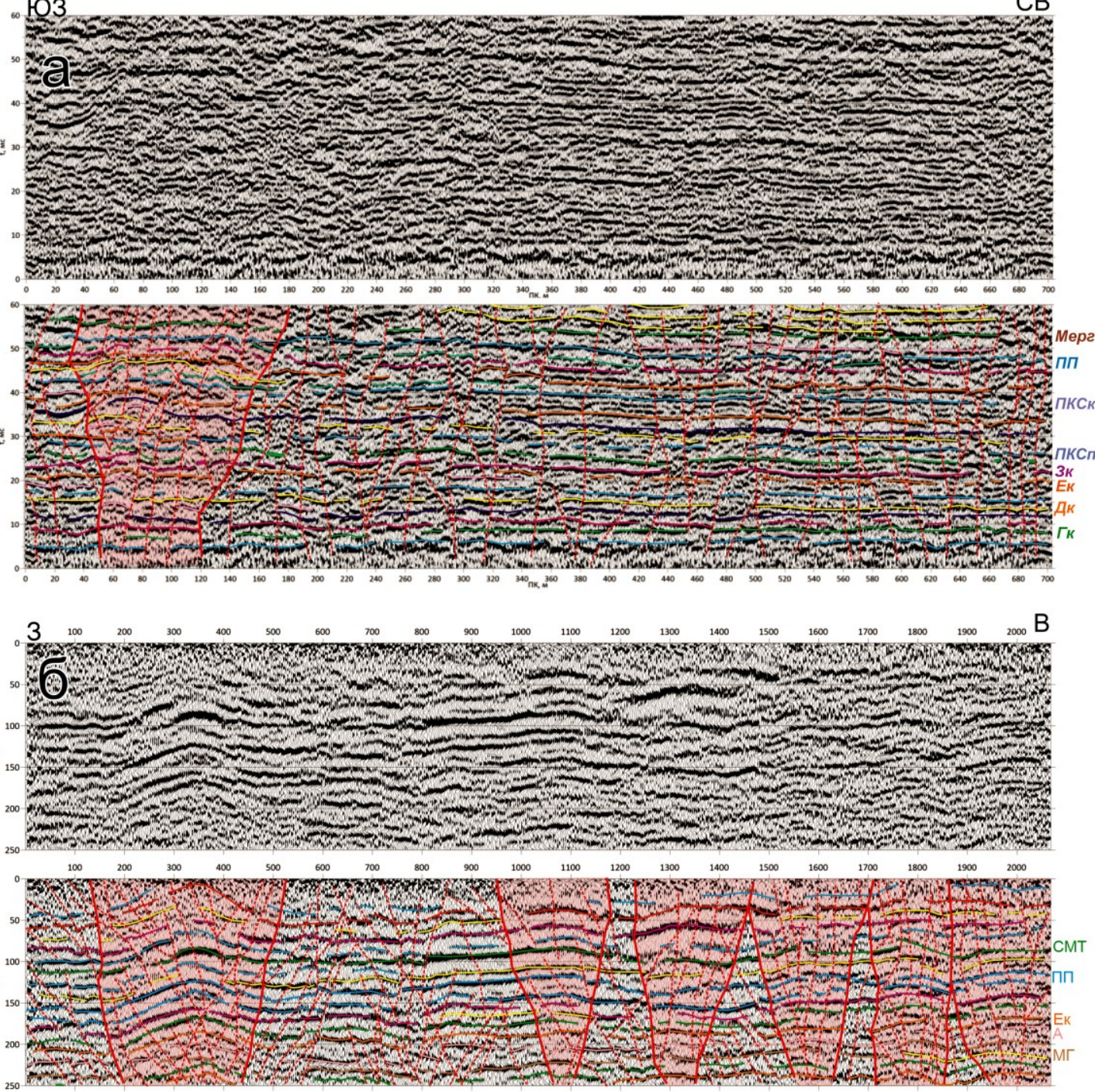

3

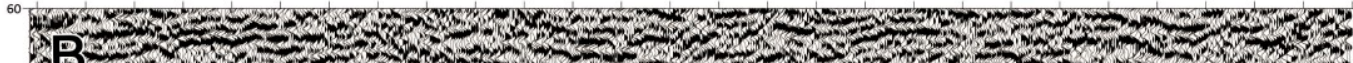
I.

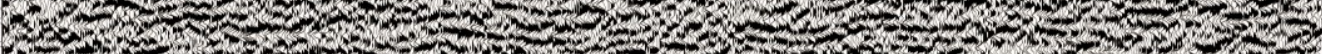

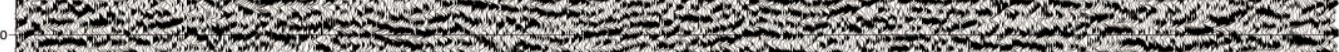

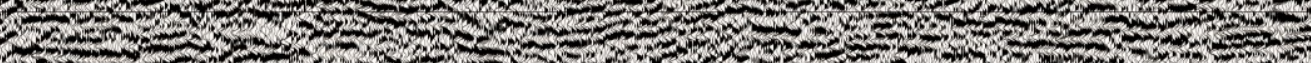

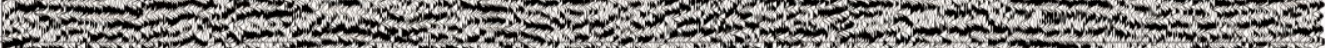

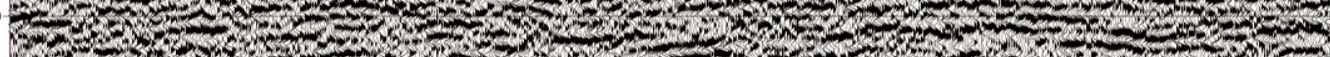

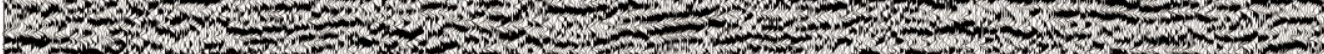

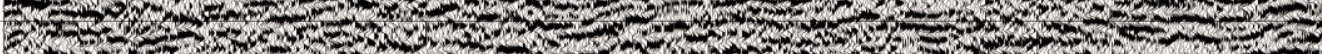

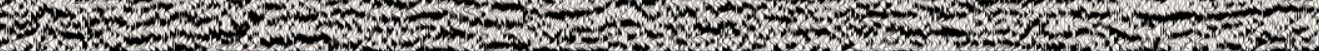

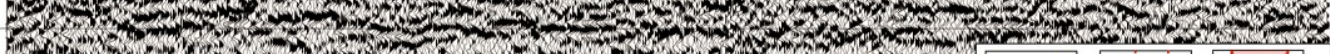

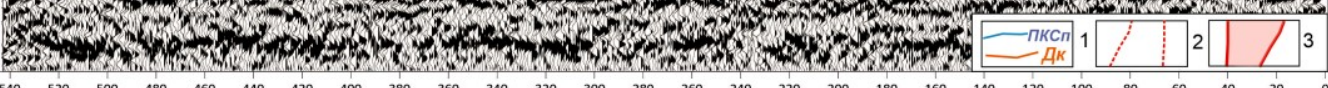

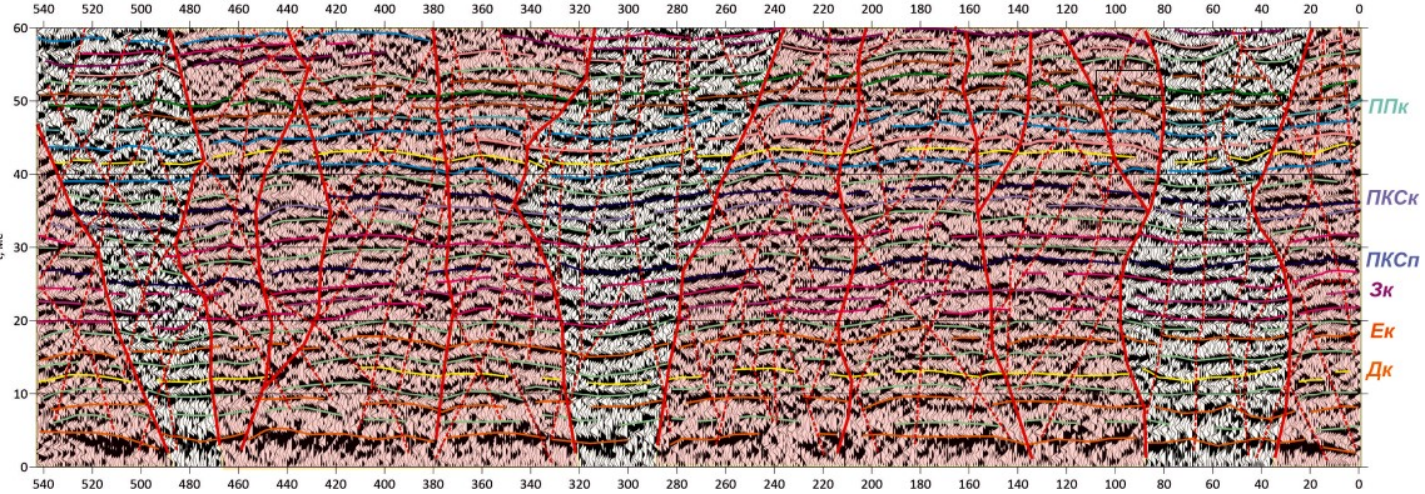


Рис. 1. Временные разрезы и их структурная интерпретация: а - подземный профиль по межблоковыму диагональному штреку 4-5 западных блоков 2-3 юго-западной панели; б - наземный профиль 5110Б4; в - подземный профиль по выемочному штреку 4 западного блока 2-3 юго-западной панели.

Условные обозначения: 1 - отражающие поверхности; 2 - границы блоков, выделяемые по перерывам и смещениям отражающих поверхностей; 3 - крупные блоки с выпуклым характером отражающих поверхностей сопоставимые с антиклинальными структурами. Буквенные сокращения: Мерг - маркирующий пласт мергеля, СМТ - соляно-мергельная толща, ПП - переходная пачка, ПКС - покровная каменная соль;

3, Е, Д, А - пласты карналлитовой и сильвинитовой зон; МГ - маркирующий глинистый горизонт

Ни в субвертикальной ориентировке границ тектонических (складчатых) блоков, ни в симметричной форме участков с антиклинальным строением не фиксируются проявления западной вергенции.

Блоковые границы и антиклинальные участки соляной толщи прослеживаются и в (нижней части) надсоляной толщи, то есть по характеру складчатости не различаются. «Корни» антиклинальных структур локализованы в подстилающей каменной соли (рис. 3б).

В распределении ширины тектонических блоков фиксируется дискретность (полимодальность): 10-35, 40-65, 150-200, около 320 м, которая сопоставляется с некоторыми порядками складок, отвечающих многопластовым и сквозным (рис. 2, 3), выделенным в работах $[1,4]$.

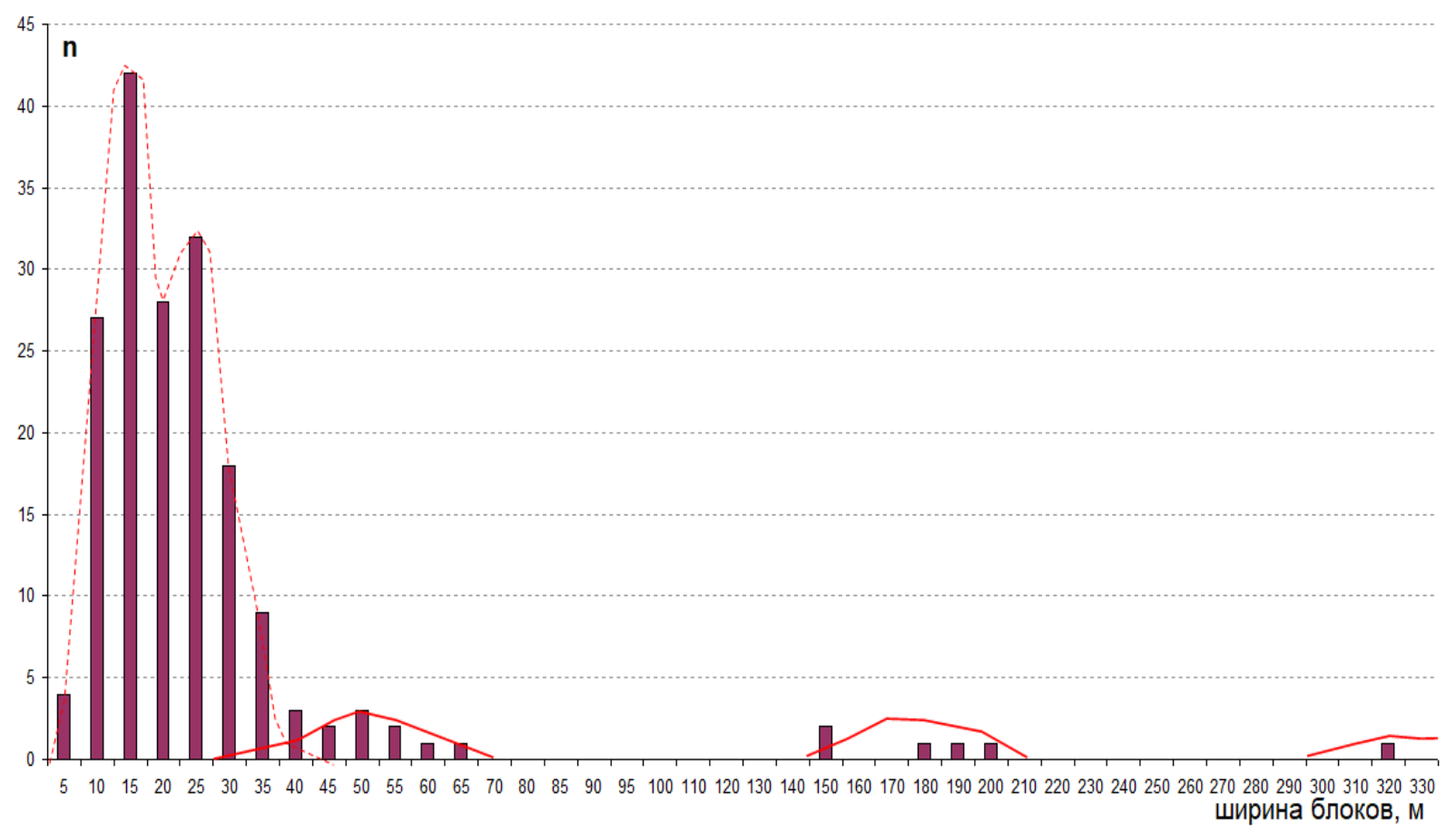

Рис. 2. Гистограмма распределения ширины складчатых блоков (пунктирная кривая) и антиклинальных участков (сплошная)

Таким образом, структура верхней части соляной толщи (включающей сильвинитовую и карналлитовую зоны, покровную каменную соль) и нижней части надсоляной (соляно-мергельная толща) характеризуется весьма сложным строением. Здесь выделены как субвертикальные границы между складчатыми коробчатыми блоками, ограниченными килевидными синклиналями, так и более крупные участки с симметричным антиклинальным строением и их скопления. Субвертикальные границы блоков дают основание полагать, что в целом на уровне двух толщ главным механизмом складчатости был продольный изгиб. Наличие отдельных антиклинальных 
участков и их скоплений, чередующихся с синклинальными, может быть связано с скольжением слоистой толщи по неровной поверхности, вероятно, подошве подстилающей каменной соли.

Следовательно, сейсмические временные разрезы, выполненные в условиях малых глубин Верхнекамского месторождения, весьма информативны для расшифровки геологических структур, а на профилях протяженностью 500-2000 м вполне могут быть выделены объекты шириной от 10 до 300 м и более.

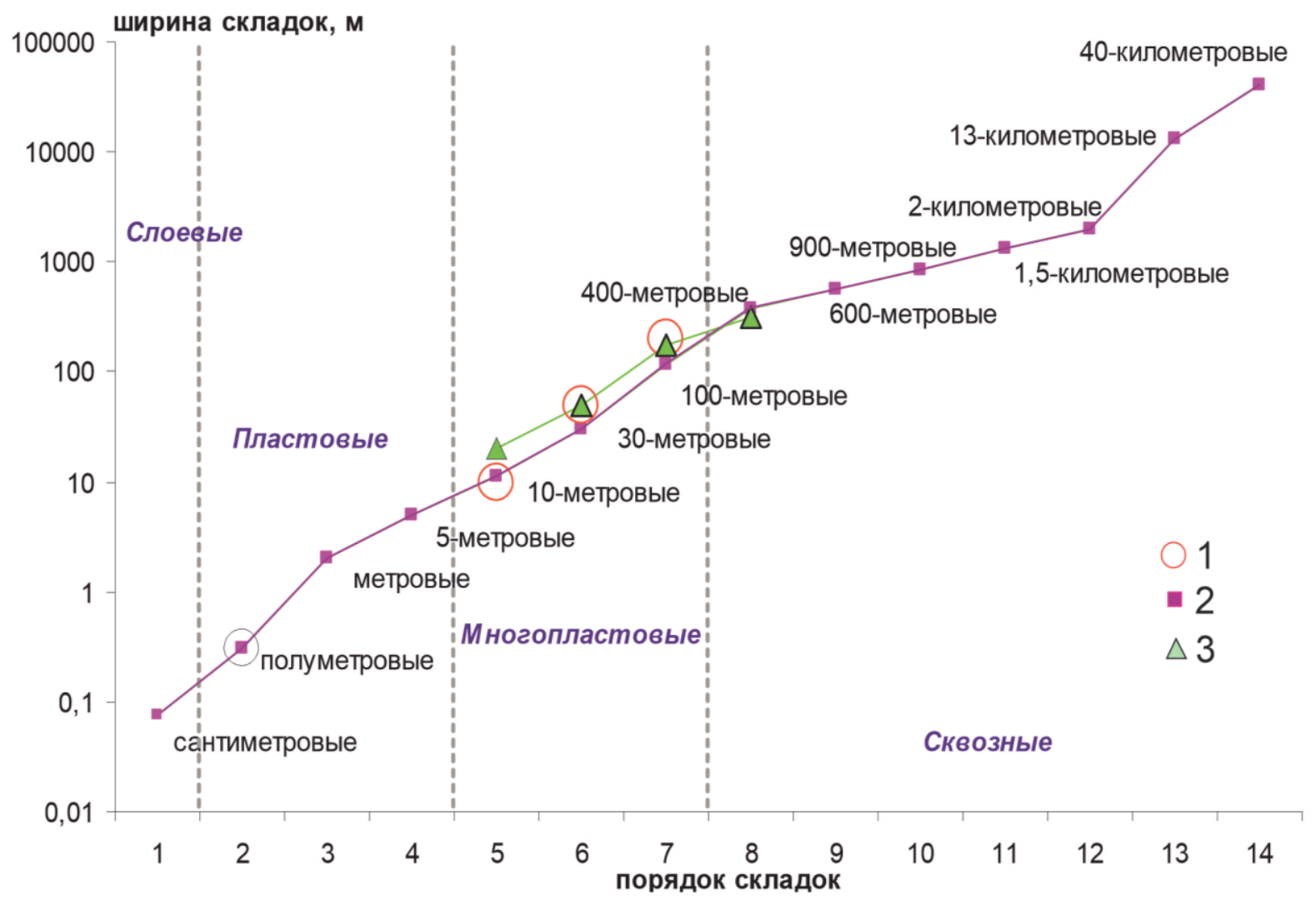

Pис. 3. Положение выявленных на сейсморазведочных разрезах структур (3) на общей схеме типизации складок Верхнекамского месторождения:

1 - четыре уровня иерархии складок выделенных Б.М. Голубевым [1] на шахтном поле БКПРУ-1;

2 - структуры, выделенные на шахтном поле БКПРУ-2 и структурной карте соляной залежи всего месторождения [4]

Работа выполнена при финансировании гранта РФФИ № 20-45-596017.

\section{БИБЛИОГРАФИЧЕСКИЙ СПИСОК}

1. Голубев Б.М. Морфологические особенности складок внутри калийной толщи Верхнекамского месторождения и условия их формирования // Докл. АН СССР. - 1972. - Т. 204, № 3. - С. 671-673.

2. Санфиров И.А., Бабкин А.И. Методические особенности шахтных сейсмоакустических исследований на Верхнекамском калийном месторождении солей // Горный информационно-аналитический бюллетень. - 2007. - № 11. - С. 145-154.

3. Санфиров И.А., Бабкин А.И,. Ярославцев А.Г, Прийма Г.Ю,.Фатькин К.Б. Сейсморазведочные исследования условий разработки калийной залежи // Геофизика. - 2011. - № 5. - С. 53-58.

4. Чайковский И.И. Иерархия и природа складок в солях Верхнекамского месторождения // Проблемы минералогии, петрографии и металлогении: науч. чтения памяти П.Н. Чирвинского / ПГУ [и др.]. Пермь, 2011. - Вып. 14. - С. 260-271. 